\title{
Aktivitas Olahraga dengan Kejadian Sindrom Premenstruasi pada Anggota Perempuan UKM INKAI UNS
}

\author{
Arantika Meidya Pratiwi ${ }^{1}$ \\ ${ }^{1}$ Sekolah Tinggi IImu Kesehatan Alma Ata Yogyakarta \\ Jalan Ringroad Barat Daya No 1 Tamantirto, Kasihan, Bantul Yogyakarta
}

\begin{abstract}
Abstrak
Tujuan penelitian ini untuk mengetahui hubungan antara aktivitas olahraga dengan sindrom premenstruasi. Metode penelitian menggunakan teknik observasional analitik dengan pendekatan cross sectional. Dilaksanakan di UKM (Unit Kegiatan Mahasiswa) INKAI (Institut Karate Indonesia) UNS, bulan Juni 2012. Sampel 36 perempuan dari populasi 40 perempuan, diambil secara simple random sampling. Uji analisis dengan $\alpha=0,05$ diperoleh nilai korelasi Spearman rank -0,821 menunjukkan kekuatan korelasi sangat kuat dengan arah korelasi negatif. Nilai signifikasi 0,000 lebih kecil dari 0,05 menunjukkan HO ditolak dan Ha diterima. Kesimpulan yang diperoleh adalah ada hubungan negatif antara aktivitas olahraga dengan sindrom premenstruasi, yaitu semakin besar nilai aktivitas olahraga maka semakin kecil nilai sindrom premenstruasi.
\end{abstract}

Kata kunci: Aktivitas Olahraga, Sindrom Premenstruasi, Perempuan

\section{Sports and The Occurrence of Premenstrual Syndrome on women member of UKM INKAI UNS}

\begin{abstract}
The purpose of this study is to determine the relationship between sport activies with premenstrual syndrome. Observational research methods using analytic techniques with cross sectional approach. This research was conducted at UKM (Unit of Student Activity) INKAI (Institute Karate Indonesia) UNS, on June 2012. The 36 sample of population from 40 of woman member was taken by simple random sampling. Analysis test with $\alpha=0,05$ obtained of Spearman rank correlation value at $-0,821$ that indicated strengthen correlation in negative direction. The significance value are 0,000 smaller than 0,05 that indicated $\mathrm{Ho}$ was rejected and $\mathrm{Ha}$ was accepted. The conclusion are any negative relationship between sports activities with the premenstrual syndrome, if the value of sports activity was higher the value of premenstrual syndrome was lower.
\end{abstract}

Keywords: Sports Activities, Premenstrual Syndrome, Women

Info Artikel:

Artikel dikirim pada 08 Januari 2014

Artikel diterima pada 15 Januari 2014

\section{Pendahuluan}

Setiap bulan secara periodik, seorang wanita normal akan mengalami peristiwa reproduksi yang disebut menstruasi. Menstruasi yang terjadi terkadang diikuti dengan gangguan-gangguan seperti gangguan siklus, dysmenorrhea, dan sindrom premenstruasi (Premenstrual Syndrome, PMS).

Sindrom premenstruasi merupakan kumpulan gejala fisik, psikologis, dan perilaku yang terjadi selama akhir fase luteal dalam siklus menstruasi dan berakhir saat menstruasi datang atau bisa berlangsung terus sampai menstruasi berhenti. Saryono dan Sejati W (2009) menyebutkan bahwa sindrom premenstruasi terjadi pada $70 \%-90 \%$ wanita pada usia subur ${ }^{1}$. Disamping itu, Bayer Schering Pharma juga memprakarsai studi yang dilakukan lembaga penelitian independen, Juli 2008, dengan jumlah responden 1.602 orang di Australia, Hongkong, Pakistan, dan Thailand. Hasilnya 22\% dari wanita di 
Asia Pasifik mengalami PMS. Sindrom premenstruasi sedang diderita $3,9 \%$ wanita dan $1,1 \%$ mengalami sindrom premenstruasi berat ${ }^{2}$.

Sebagian besar wanita menganggap bahwa PMS bukan suatu kondisi yang serius, sehingga tidak melakukan upaya pencegahan ataupun pengobatan. Padahal sindrom premenstruasi ini dapat juga berubah menjadi kondisi yang serius seperti depresi. Salah satu yang dapat dilakukan untuk mengurangi gejala PMS adalah dengan melakukan perubahan gaya hidup. Hal-hal seperti membatasi konsumsi kafein dan olahraga teratur dapat mengurangi PMS pada wanita ${ }^{3}$.

Olahraga yoga, aerobik, ataupun peregangan sederhana bisa mengurangi gangguan-gangguan PMS seperti kram, sakit punggung, nyeri dan ketegangan otot,dan stress ${ }^{4}$. Manfaat dari olahraga yang bisa kita dapatkan, namun kebiasaan berolahraga sudah jarang sekali dimiliki oleh masyarakat terutama perempuan. Berdasarkan penelitian, sekitar 28\% kematian akibat penyakit dilatarbelakangi oleh gaya hidup sedentary (kurang gerak). Penduduk Amerika yang memiliki kebiasaan berolahraga aktif hanya $20 \%$ dan $60 \%$ penduduk tidak memiliki kebiasan berolahraga 5 .

Penelitian hubungan aktivitas olahraga pernah dilakukan oleh Andayani (2010) dengan judul "Hubungan Aktivitas Olahraga dengan Dysmenorrhea pada Siswi Kelas X di SMK Negeri 6 Surakarta" yang menggunakan jenis penelitian analitik dengan pendekatan cross sectional. Sebagai responden penelitian tersebut adalah siswi kelas X SMK Negeri 6 Surakarta. Hasil penelitian tersebut menunjukkan aktivitas olahraga mempunyai pengaruh terhadap kejadian dismenorea. Persamaan penelitian ini terletak pada salah satu variabel penelitian yaitu aktivitas olahraga. Perbedaannya terletak pada variabel terikatnya yaitu sindrom premenstruasi ${ }^{6}$.

Dari studi pendahuluan yang dilakukan pada 10 anggota perempuan UKM INKAI UNS didapatkan hasil bahwa 90\% mahasiswi berolahraga cukup dan $10 \%$ mahasisiwi berolahraga kurang. Sebanyak $80 \%$ mahasiswi mengalami PMS ringan dan $20 \%$ mahasiswi mengalami PMS sedang.

\section{Bahan dan Metode}

Desain penelitian yang digunakan adalah observasional analitik dengan pendekatan cross sectional. Penelitian ini dilaksanakan di UKM INKAI Universitas Sebelas Maret Surakarta pada bulan Juni 2012. Populasinya adalah seluruh anggota perempuan UKM INKAI Universitas Sebelas Maret Surakarta yaitu 40 orang. Teknik pengambilan sampel pada penelitian ini secara random dengan cara simple random sampling. Sebanyak 40 orang memenuhi kriteria (1)Anggota perempuan UKM INKAI Universitas Sebelas Maret Surakarta (2) Hadir saat penelitian berlangsung.(3) Tidak memiliki penyakit sistemik dan genitalia (4) tidak mengkonsumsi obat-obatan tertentu, alkohol, NAPZA, merokok (5) Bersedia menjadi responden. Alat ukur pengumpulan data pada penelitian ini adalah kuesioner yang sudah diuji validitas dan reliabilitasnya. Data yang diperoleh dalam penelitian ini akan dianalisa dengan metode analisis korelasi Spearman rank dengan bantuan software komputer.

\section{Hasil dan Pembahasan}

\section{Karakteristik Responden}

Penelitian dilakukan di UKM (Unit Kegiatan Mahasiswa) INKAI (Institut Karate Indonesia) Universitas Sebelas Maret Surakarta pada bulan Juni 2012. Responden berjumlah 36 perempuan yang semuanya masih berstatus mahasiswa. Subjek penelitian yang terpilih telah mendapat menstruasi dan memenuhi kriteria inklusi.

\section{Umur}

Tabel 1.1 Karakteristik Usia Anggota Perempuan UKM INKAI UNS

\begin{tabular}{ccc}
\hline Karakteristik Usia & Frekuensi & Persentase $(\%)$ \\
\hline 18 & 6 & 23.1 \\
19 & 7 & 26.9 \\
20 & 11 & 42.3 \\
21 & 9 & 34.6 \\
22 & 3 & 11.5 \\
\hline Total & 36 & 100 \\
\hline
\end{tabular}

Sumber : Data Primer (2012)

Umur responden penelitian yang terpilih berkisar antara 18-22 tahun. Jumlah terbanyak responden berdasarkan karakteristik umur adalah usia 20 tahun yakni sebanyak $42,3 \%$, dan yang terendah yaitu usia 22 tahun sebanyak $11,5 \%$.

\section{Menstruasi dan usia menarche}

Semua responden telah mendapatkan menstruasi dan mendapatkan menstruasi pertamanya pada kisaran umur 12-15 tahun.

Data yang didapat menunjukkan bahwa paling banyak responden mengalami menarche pada usia 13 dan 14 tahun yaitu sebanyak 38,9\%. Responden yang mengalami menarche pada usia 12 tahun sebanyak $13,9 \%$ dan paling sedikit pada usia 15 tahun yaitu sebanyak $8,3 \%$. 
Tabel 2.1 Karakteristik Usia Menarche Anggota Perempuan UKM INKAI UNS Juni 2012

\begin{tabular}{ccc}
\hline $\begin{array}{c}\text { Karakteristik Usia } \\
\text { Menarche }\end{array}$ & Frekuensi & Persentase (\%) \\
\hline 12 & 5 & 13.9 \\
13 & 14 & 38.9 \\
14 & 14 & 38.9 \\
15 & 3 & 8.3 \\
\hline Total & 36 & 100 \\
\hline
\end{tabular}

Sumber : Data Primer (2012)

3. Keteraturan berolahraga dalam tiga bulan terakhir

Tabel 3.1 Karakteristik Keteraturan Berolahraga dalam Tiga Bulan Terakhir Anggota Perempuan UKM INKAI UNS Juni 2012

\begin{tabular}{lcc}
\hline $\begin{array}{c}\text { Karakteristik keteraturan } \\
\text { olahraga }\end{array}$ & Frekuensi & $\begin{array}{c}\text { Persentase } \\
(\%)\end{array}$ \\
\hline Ya & 27 & 75 \\
Tidak & 9 & 25 \\
\hline Total & 36 & 100 \\
\hline
\end{tabular}

Sumber : Data Primer (2012)

Sebanyak $75 \%$ responden berolahraga secara teratur dalam tiga bulan terakhir, sedangkan $25 \%$ responden melakukan olahraga namun tidak teratur.

\section{Data Variabel Aktivitas Olahraga}

Berdasarkan variabel aktivitas olahraganya, peneliti membagi responden menjadi dua kelompok yaitu olahraga cukup dan olahraga kurang.

Tabel 1. Distribusi Frekuensi Aktivitas Olahraga pada Anggota Perempuan UKM INKAI UNS Juni 2012

\begin{tabular}{lcc}
\hline Kategori Olahraga & Frekuensi & Persentase (\%) \\
\hline Kurang & 19 & 52.8 \\
Cukup & 17 & 47.2 \\
Total & 36 & 100 \\
\hline
\end{tabular}

Sumber : Data Primer (2012)

Data yang didapat menunjukkan bahwa $47,2 \%$ responden berolahraga secara cukup dan $52,8 \%$ melakukan aktivitas olahraga kurang.

\section{Data Variabel Sindrom Premenstruasi}

Ada 30 item pertanyaan gejala pada kuesioner sindrom premenstruasi. Gejala-gejala yang paling banyak dialami responden dapat dilihat pada tabel 4.5 .

Gejala yang paling banyak dialami responden adalah mudah tersinggung dan perubahan mood
Tabel 2. Urutan Gejala-gejala Sindrom Premenstruasi

\begin{tabular}{clcc}
\hline No. & Gejala & Jumlah & $\begin{array}{c}\text { Persentase } \\
(\%)\end{array}$ \\
\hline 1 & Mudah tersinggung & 36 & 100 \\
2 & $\begin{array}{l}\text { Perubahan mood secara } \\
\text { tiba-tiba }\end{array}$ & 36 & 100 \\
3 & Mudah marah & 35 & 97.2 \\
4 & Payudara menegang dan & 34 & 94.4 \\
5 & nyeri & 34 & 94.4 \\
\hline
\end{tabular}

Sumber : Data Primer (2012)

secara tiba-tiba yaitu sebesar $100 \%$. Mudah marah menempati urutan kedua yaitu sebanyak $97,2 \%$. Gejala lain yang paling banyak dialami responden adalah payudara menegang dan nyeri $(94,4 \%)$ dan perubahan nafsu makan $(94,4 \%)$.

Variabel sindrom premenstruasi dibagi menjadi tiga kategori yaitu kategori sindrom premenstruasi ringan, sedang, dan berat. Hasil distribusi frekuensi ketiga kategori tersebut dapat dilihat pada tabel 4.6.

Tabel 3. Distribusi Frekuensi Sindrom Premenstruasi pada Anggota Perempuan UKM INKAI UNS Juni 2012

\begin{tabular}{lcc}
\hline Kategori Sindrom & Frekuensi & Persentase (\%) \\
Premenstruasi & 16 & 44.4 \\
\hline Ringan & 18 & 50 \\
Sedang & 2 & 5.6 \\
Berat & 36 & 100 \\
Total & & \\
\hline
\end{tabular}

Sumber : Data Primer 2012

Data yang didapat menunjukkan paling banyak responden mengalami sindrom premenstruasi sedang yaitu sebanyak $50 \%$ responden, sedangkan paling sedikit responden mengalami sindrom premenstruasi berat yaitu sebanyak $5,6 \%$ responden.

\section{Uji Korelasi antara Aktivitas Olahraga dengan Sindrom Premenstruasi pada Anggota Perempuan UKM INKAI UNS}

Peneliti membagi dua kelompok aktivitas olahraga berdasarkan derajat sindrom premenstruasi, yaitu responden dengan aktivitas olahraga cukup dan responden dengan aktivitas olahraga kurang. Sedangkan derajat sindrom premenstruasi dibagi menjadi tiga yaitu sindrom premenstruasi ringan, sedang, dan berat. Hubungan antara aktivitas olahraga dengan sindrom premenstruasi pada anggota perempuan UKM INKAI UNS, dapat dideskripsikan pada tabel 4 .

Tabel 4. menunjukkan perbedaan yang bermakna antara kelompok yang berolahraga cukup dengan kelompok yang berolahraga kurang. Perbedaan yang bermakna tersebut terlihat pada 
kelompok yang berolahraga cukup sebanyak $41,7 \%$ responden hanya mengalami sindrom premenstruasi ringan, sedangkan pada kelompok olahraga kurang sebanyak $44,4 \%$ responden mengalami sindrom premenstruasi sedang. Selain itu sindrom premenstruasi berat dialami $5,6 \%$ responden dari kelompok olahraga kurang.

Tabel 4. Hubungan antara aktivitas olahraga dengan sindrom premenstruasi pada anggota perempuan UKM INKAI UNS

\begin{tabular}{lccc}
\hline & $\begin{array}{c}\text { Sindrom } \\
\text { premenstruasi }\end{array}$ & Ringan & Sedang \\
Olahraga & & & \\
\hline Olahraga kurang & 1 & 16 & 2 \\
& $(2,8 \%)$ & $(44,4 \%)$ & $(5,6 \%)$ \\
Olahraga cukup & 15 & 2 & 0 \\
& $(41,7 \%)$ & $(5,6 \%)$ & \\
\hline
\end{tabular}

Sumber: Data Primer (2012)

Setelah data tersebut diolah kemudian dilakukan pengujian data dengan menggunakan uji korelasi Spearman rank dengan tingkat kepercayaan 95\% atau $\alpha=0,05$ untuk mengetahui hubungan antara aktivitas olahraga dengan sindrom premenstruasi.

Hasil uji statistik dengan Spearman rank didapatkan hasil seperti dalam tabel 5 . berikut:

Tabel 5. Hasil Uji Statistik dengan korelasi Spearman Rank pada Anggota Perempuan UKM INKAI UNS Juni 2012

\begin{tabular}{lcc}
\hline \multicolumn{1}{c}{ Komponen } & $\begin{array}{c}\text { Kekuatan } \\
\text { Korelasi }(r)\end{array}$ & $\begin{array}{c}\text { Nilai Signifikansi } \\
(\mathrm{p})\end{array}$ \\
\hline $\begin{array}{l}\text { Aktivitas olahraga } \\
\text { terhadap sindrom } \\
\text { premenstruasi }\end{array}$ & $-0,821$ & 0,000 \\
\hline
\end{tabular}

Sumber : Data Primer 2012

\section{Hubungan antara Aktivitas Olahraga dengan Sindrom Premenstruasi pada Anggota Perempuan UKM INKAI UNS}

Hasil pengolahan data didapatkan nilai korelasi Spearman rank sebesar -0,821 yang artinya kekuatan korelasi yang terjadi adalah sangat kuat. Nilai korelasi Spearman rank menunjukkan arah korelasi negatif atau berlawanan arah, sehingga dapat ditarik kesimpulan semakin tinggi aktivitas olahraga maka semakin rendah tingkat sindrom premenstruasi. Nilai signifikansi $(p)$ yang diperoleh adalah 0,000 yang lebih kecil daripada 0,05 . Maka hal ini menunjukkan bahwa $\mathrm{H}_{0}$ ditolak dan $\mathrm{H}_{\mathrm{a}}$ diterima, sehingga disimpulkan bahwa ada hubungan antara aktivitas olahraga dengan sindrom premenstruasi.

Berdasarkan hasil penelitian dapat dibuktikan bahwa hipotesis diterima yaitu terdapat hubungan antara aktivitas olahraga dengan sindrom premenstruasi. Hal ini sesuai tinjauan teori menurut Saryono dan Sejati (2009) yang menyatakan bahwa pada sebagian besar wanita, olahraga mampu mengurangi gejala PMS yaitu mengurangi kelelahan, stress dan meningkatkan kesehatan tubuh. Olahraga meningkatkan rangsang simpatis, yaitu suatu kondisi yang menurunkan detak jantung dan mengurangi sensasi cemas. Olahraga teratur juga dapat mengurangi stress, meningkatkan pola tidur yang teratur, dan meningkatkan produksi endorphin (pembunuh rasa sakit alami tubuh), dimana hal ini dapat meningkatkan kadar serotonin. Serotonin merupakan neotransmiter yang diproduksi di otak yang berperan penting dalam pengaturan mood, kecemasan, gairah seksual, dan perubahan suasana hati ${ }^{1}$.

Rasa nyeri karena retensi cairan dan rasa tidak enak pada payudara juga berkurang karena pengaruh olahraga terhadap neurotransmitter sentral misalnya $\beta$-endorphin dan atau berkurangnya prostaglandin 2. Selain itu beta endorphin dapat merelaksasikan otot-otot dalam tubuh terutama otot sekitar bagian perut yang dapat menyebabkan aliran darah menjadi lancar sehingga nyeri dapat berkurang. Endorphin juga berperan dalam mengendalikan nafsu makan dan pelepasan hormon seks ${ }^{7}$. Manfaat olahraga akan dapat lebih dirasakan apabila dilakukan secara cukup. Olahraga cukup artinya dilakukan sesuai takarannya, yaitu dilakukan 3-5 kali dalam satu minggu selama 20-60 menit dan mencapai denyut nadi sasaran. Jika olahraga dilakukan kurang dari takarannya maka manfaat olahraga yang dirasakan juga kurang maksimal. Hal ini yang menyebabkan responden yang berolahraga cukup mayoritas hanya mengalami PMS ringan. Responden yang berolahraga cukup, mendapatkan manfaat olahraga lebih maksimal, sehingga gejala PMS yang dirasakan lebih sedikit atau lebih ringan. Sedangkan responden yang berolahraga kurang, mayoritas mengalami PMS sedang hingga berat karena manfaat dari olahraga kurang dapat dirasakan oleh responden kelompok olahraga kurang.

\section{Simpulan dan Saran}

\section{Simpulan}

Ada hubungan antara aktivitas olahraga dengan sindrom premenstruasi dengan arah hubungan negatif yaitu semakin tinggi aktivitas olahraga maka semakin rendah tingkat sindrom premenstruasi.

\section{Saran}

1. Bagi pengurus Unit Kegiatan Mahasiswa (UKM) Institut Karate Indonesia (INKAI) Universitas Sebelas Maret, diharapkan dapat menerapkan 
program latihan yang cukup sesuai dengan takaran olahraga yang meliputi frekuensi olahraga 3-5 kali dalam satu minggu, intensitas mencapai denyut jantung sasaran olahraga, dan time (waktu) olahraga selama 20-60 menit. Selain itu juga diharapkan dapat lebih memotivasi anggotanya untuk lebih giat berolahraga secara cukup.

2. Bagi perempuan, diharapkan agar para anggota perempuan UKM INKAI UNS pada khususnya dan semua perempuan pada umumnya tetap mempertahankan dan meningkatkan aktivitas olahraga secara cukup dan teratur sebagai terapi atau tindakan preventif untuk sindrom premenstruasi. Selain itu juga diharapkan selalu menambah wawasan mengenai pentingnya olahraga bagi kesehatan perempuan terutama kaitannya dengan sindrom premenstruasi.

3. Bagi peneliti, diharapkan untuk penelitian selanjutnya, peneliti dapat meneliti lebih lanjut variabel-variabel lain yang menjadi faktor yang mempengaruhi sindrom premenstruasi seperti faktor hormonal, kimiawi, genetik dan psikologis. Juga diharapkan untuk lebih banyak menambah sumber pustaka yang digunakan.

\section{Daftar Rujukan}

1. Saryono dan Sejati W. 2009. Sindrom Premenstruasi. Yogyakarta : Nuha Medika. Hal: 17-24, 27-32, 47-8.

2. Emilia, O. 2008. "Premenstrual Syndrome (PMS) and Premenstrual Dysphoric Disorder (PMDD) in Indonesian Women". Vol 40 hal 148-53. http://bik. fk.ugm.ac.id/download/07-OVA-SEP\%2008.pdf. Last update November 2008 (Diakses tanggal 2 Maret 2012).

3. Smith MA dan Shimp LA. 2000. 20 Common Problems in Women's Health Care. Singapore : Mc Graw Hill Companies. Hal : 402-404.

4. Kelly T. 2007. 50 Rahasia Alami Meringankan Sindrom Premenstruasi. Jakarta : Erlangga. Hal : 32-36.

5. Cahyono JBSB. 2008. Gaya Hidup dan Penyakit Modern. Yogyakarta: Kanisius. Hal: 196.

6. Andayani WN. 2010. Hubungan Antara Aktifitas Olahraga dengan Kejadian Dismenorea pada Siswi Kelas X SMK N 6 Surakarta. Surakarta: Universitas Sebelas Maret. Karya Tulis IImiah.

7. Tania, T. 2007. Strenous Running and Endorphins. Available at: www.path.org/files/Indonesia163pdf.On : 10 Maret 2012. 